amounts but that less than 5 per cent of the crossover product $\mathrm{CH}_{3} \mathrm{CD}_{3}$ was formed:

$$
\begin{aligned}
&\left(\mathrm{CH}_{3}\right)_{3} \mathrm{AuPPh}_{3}+ \longrightarrow \\
&\left(\mathrm{CD}_{3}\right)_{3} \mathrm{AuPPh}_{3} \longrightarrow \mathrm{C}_{2} \mathrm{H}_{6}+\mathrm{CH}_{3} \mathrm{AuPPh}_{3} \\
& \longrightarrow \mathrm{CH}_{3} \mathrm{CD}_{3} \\
& \longrightarrow \mathrm{C}_{2} \mathrm{D}_{4}+\mathrm{CD}_{3} \mathrm{AuPPh}_{3}
\end{aligned}
$$

\section{Conclusions}

Organogold chemistry is in its infancy. It offers many attractions and recent work has shown that it is of significant interest to organometallic chemists not only because of the wide range of compounds available but also because their reaction mechanisms are easily studied.
Kochi and his co-workers have shown for instance the usefulness of gold as a catalyst for mechanistic studies since reactions are readily probed by $\mathrm{nmr}$ studies in solution and intermediates identified.

Much of the chemistry of $\mathrm{Au}(\mathrm{I})$ and $\mathrm{Au}(\mathrm{III})$ organo-complexes would appear to be similar to that of other metal ions possessing the $\mathrm{d}^{10}$ and $\mathrm{d}^{8}$ configurations but there are differences in the thermodynamic and kinetic stabilities of such complexes.

\section{References}

1 A. Johnson and R. J. Puddephatt, F. Chem. Soc., Dalton Trans., 1975, (2), 115

2 A. Tamaki, S. A. Magennis and J. K. Kochi, f. Am Chem. Soc., 1974, 96, (19), 6140, and references therein

3 G. E. Coates and C. Parkin, f. Chem. Soc., 1963. Pt. I, 421

\title{
Inlay-Clad Gold Alloys for Telephone Contacts
}

The use of inlay-clad gold alloys as an alternative to electrodeposited gold is progressing in a number of electrical and electronic applications, and is currently proving of interest to the Bell Telephone System. The analysis of a number of gold alloys in inlay form recently compiled by R. J. Russell (Gold Bull., 1976, 9, (1), 2-6) showed that this approach offered possibilities for the contacts in a TRIMLINE telephone hand-set, and a paper presented to the 8th Annual Connector Symposium held at Cherry Hill, New Jersey in October last year reports on a detailed assessment of inlaid gold for this application.

The paper, by M. U. Rao and A. J. Molchan of Bell Telephone Laboratories, Indianapolis, and R. J. Russell of Technical Materials, Lincoln, Rhode Island, shows that over a three-month evaluation a 6 per cent nickel-gold alloy for this specific contact spring application gave acceptable properties in terms of porosity, wear, arc erosion and ease of forming and was comparable to a cobalt-hardened electrodeposited gold in use for the past eight years, with appreciable savings in cost.

The switch is expected to withstand at least 50,000 operations over a life of about 20 years. The normally closed contacts carry between 20 and $200 \mathrm{~mA}$, the normal force required to separate the contacts being $150 \mathrm{~g}$ minimum. Five hand-sets from the Western Electric production line were fitted with the prototype gold-inlay contacts and were tested for 300,000 operations-far exceeding the likely service lifealongside five normal hand-sets with the electrodeposited gold contacts. All ten sets were then submitted to the Western Electric procedure for initial testing and all were found to be acceptable.

The hardness of the 6 per cent nickel-gold alloy in its rolled inlay form was $220 \mathrm{KHN}$ as against 140 to $180 \mathrm{KHN}$ for the electrodeposited hard gold, which showed a greater degree of smearing in the wear tests.

The contacts of the switch under investigation are in series with the telephone line and must meet telephone system requirements for speech transmission, and a further series of tests was used to operate the contacts through 50,000 make and break cycles under 48 volts DC with a high level of inductive loading.
The contact resistance was measured before and after the test runs. An increase from around $10 \mathrm{~m} \Omega$ to less than $30 \mathrm{~m} \Omega$ was found. (Noise in a telephone set generally appears at around $60 \mathrm{~m} \Omega$.) Arc erosion on both the inlaid and the electrodeposited contacts was much the same in these intentionally severe conditions.

The 6 per cent nickel-gold alloy was chosen for the inlay since its hardness, wear characteristics and contact resistance data showed the likelihood of its acceptability as a substitute for electroplated hard gold. Other alloys are to be investigated later.

The authors conclude that the clad-inlay approach offers the best route to substantial cost savings at present production levels when compared with alternatives such as selective plating or welded-on contacts. Replacement of the electroplated springs with inlay contact springs would not alter assembly procedures, while the expense of the one-off re-tooling would be offset by economies in the cost of production.

\section{Constitution of Gold Alloy Electrodeposits}

The constitution of a gold alloy in electrodeposited form-usually quite different from that of the same alloy in cast or wrought form-is of importance in determining its resistance to oxidation or corrosion in service, but so far very little information is available on this subject.

An X-ray study by H. Grossman and F. Horn of DoDuco, Pforzheim, carried out with $\mathrm{H}$. Bauer of the University of Giessen, on the structure of hard gold deposits from a sulphite bath ( $\mathcal{F}$. Less-Common Metals, 1975, 43, 291-294) shows that while a deposit containing 0.3 per cent cobalt virtually retains the lattice parameter of pure gold, two highly alloyed deposits, one having 15 per cent nickel and the other 35 per cent copper, show the presence of a new face-centred cubic phase with almost all the alloying elements in solid solution. 